DEIARTAME.NTO DE ZOOTECNIA

Diretor substituto: Prof. Dr. Fernando Andreasi

\title{
LEVANTAMENTO DOS ELEMENTOS MINERAIS EM PLANTAS FORRAGEIRAS DE AREAS DELIMITADAS DO ESTADO DE SÃO PAULO. IV - ZINCO *
}

\author{
(SURVF:Y ON TIF: MINGRAL ELFMENTS IN PASTURE PLANTS \\ PRODUCF:D IN RESTRICTED AREAS OF SAOO PALLO STATE \\ BRAZII. IV - ZINC)
}

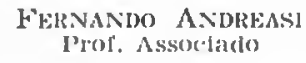

Prot. Associato
For \\ Jō̄o Silva Marcoxdess Veig.l \\ Instrutor
}

Cissio Xavien de MeNdonga JR.
Instrutor

Flavio Prada

Instrutor

Relaçōes inadequadas de zinco e outros micronutrientes, tem sido experimentalmente estudadas em animais de laboratório através da administração de dietas purificadas $(11,27)$.

UNDERWOOD (30), em 1956, prognosticou que, em razão do elevado conteúdo dêste elemento existente nas plantas, pareceria bastante improvável a ocorrência desta deficiência em animais de interêsse cconômico, mantidos em condiçōes naturais ou em estabulaçāo.

De fato, segundo Gladstones \& Loneracian (10), o efeito desta carência em algumas leguminosas e gramincas se faz sentir mais pronunciadamente, sôbre o rendimento da massa vegetal produzida, do que em relação à concentração do elemento na planta.

Entretanto, Tucker \& SALion (29) haviam, já em 1955, diagnosticado, em suinos, uma deficiência dêste micronutriente, determinando o sindrome para(1ueratose condicionado por vários fatôres, entre os quais: a) insuficiência do mesmo na ração; b) altos niveis de cálcio e fósforo nos alimentos; c) exigência elevada dessa espécie, pelo menos, em relação a êsse elemento.

VALEE (31) apresentou excelente revisão sôbre a paraqueratose em suinos, em crescimento, seguido por HoEfer et alii (14),

\footnotetext{
- Parte do presente trabatho fol realizada com auxilio da Fundacão de Amparo à Pesquisa (io Fistado de são Paulo e da Fundaça Rockefeller.

Trabalho apresentado no XII Congresso Brasileiro de Medicina Veterinária reallzado em Porto Alegre (IRGS), em 1970.
} 
que abordaram o papel das interrelações de cálcio, zinco, ferro e cobre na produção da doença; OBERLFAs et alii (20), atribuiram o ácido fítico como sendo o fator responsável pela mais alıa exigência em zinco nessa espécic; Sirith et alii (28) avaliaram o ganho, conversão e casos de paraqueratose em suinos submetidos a diferentes fontes de proteína e carboidratos com e sem adição do micronutriente; POND et alii (25) estudaram os efeitos dos niveis do mesmo relacionados aos teores de cálcio e concentração de milho na ração sôbre o ganho de pêso e ocorrência da doença; $\mathrm{cm}$ publicaçāo ulterior, Poxid et alii (24) rerificaram a influência do ólco de milho, cádmio e diferentes niveis de zinco sôbre o crescimento e incidência de paraqueratose em bácoros.

Contudo, sòmente em 1960, enquanto Milluel \& Millatr (17), descreviam uma deficiência dêste elemento, experimentalmente induzida, em bezerros holandêses, LegG \& Sears (16), observaram, em bovinos mantidos em condiçōes naturais, lesōes semelhantes àquelas descritas em ratos que foram submetidos à dieta deficiente em zinco.

Contrariando a assertiva de UNDERWOOn (30), de que as plantas forrageiras são normalmente ricas nêsse mineral, outros autores $(7,8,13,16)$ mostraram que algumas espécies podem apresentar niveis insuficientes do elemento.

D'outra parte, as relações entre cảlcio, magnésio e zinco (12), e as exigências deste último, em funçāo a diferentes teores de cálcio na ração (13), interrelações, cobre e zinco influenciadas pela presença do cílcio e molibdeno (8), foram focalizadas $\mathrm{cm}$ bovinos mantidos em condições de pastejo.

Miller \& Miller (18), induziram com dictas purificadas, a deficiência $\mathrm{cm}$ bezerros e $\mathrm{cm}$ seguida, recuperam a saúde dos animais com diferentes niveis do mineral, enquanto Milis et alii (19), chegaram à conclusão de que a suplementação de $0,2 \mathrm{mg} \mathrm{Zn} / \mathrm{kg}$ pêso por dia, ou de 10 a 15 p.p.m. na ração, proporcionou, curva de crescimento normal em bezerros e ovinos destacando ainda a incapacidade destas espécies em armazenar excessos dêste elemento para ulterior utilização.

Por outro lado, níveis tão altos, como 100 p.p.m., foram assinalados por OTT et alii (21) que, utilizando dictas purificadas, obtiveram em ovelhas, adequado ritmo de crescimento e conversão alimentar. Posteriormente, OTT et alii (22) utilizando a mesma linha de investigaçāo anterior (21), sugeriram que, em ovelhas, as exigências situam-se entre 18 c 33 p.p.m. após surpreender significante efeito linear, do zinco da dieta sôbre o ganho de pêso e eficiência alimentar. 
Na litcratura compulsada, não nos foi dado encontrar referência de trabalinos realizados na América Latina, quer sôbre a riqueza dêsse mineral em plantas forrageiras, quer em relação à identificação de deficiência de zinco nessa área.

A presente investigação $1 \mathrm{~cm}$ por objetivo realizar um levantamento dos niveis dêsses elementos contidos em três plantas forrageiras mais comuns em zonas delimitadas do Estado de São Paulo e relacioná-los às exigências nutricionais dos animais de interêsse econômico.

\section{RISUITADOS F: DISCUSSAO}

As plantas forrageiras - capim Colonião (Panicum maximum), Jaraguá [Hyparthenia ma (Nees) Stapf] e Gordura (Melinis mimutiflor(t) - utilizadas nêste estudo, provieram de diferentes municipios do Estado de São Paulo.

O critério adotado durante a colheita, observando quatro diferentes tipos de solos assim como duas estações bem definidas ao lado dos cuidados dispensados para evitar contaminações, remessa ao laboratório, moagem e preparo das amostras, está contido em trabalho anterior |A.NDREAsI et alii (1)|.

O método empregado para determinação do zinco, descrito por LAZAR (15), é uma condensação, ligeiramente modificada, dos métodos da AOAC (4) e de COWLING \& Milleer (5).

Dadas as dificuldades iniciais encontradas na preparação das soluções e cuidados especiais exigidos durante o desenvolvimento das diversas fases do mélodo, pareceu-nos recomendável descrever, embora de forma concisa, parte do esquema de LAzAr (15), atinente aos sucessivos tra1amentos prévios a que foram submetidas as amostras, visando a eliminação dos mais comuns interferentes, presentes em plantas, permitindo a determinação dos micro-nutrientes, entre os quais o zinco, objeto do presente trabalho.

$$
\text { I - Preparação da solução "A". }
$$

Para a preparação da solução " $A$ ", observamos o método de GIEsEKING et alii (9), cuja seqüência foi adaptada ao esquema (Fig. 1) claborado por LAZAR (15).

$$
\text { II - Preparação das soluçōes " } B \text { " } e \text { " } C \text { ". }
$$

\section{A - Reagentes:}

1 - Ácido cloridrico 1:1, destilado.

2 - Citrato de amôneo a $40 \% \dot{s}$. 
Dissolver $800 \mathrm{~g}$ de ácido cítrico p.a. em $600 \mathrm{ml}$ de água destilada e, lentamente, sob agitação, juntar $900 \mathrm{ml}$ de hidróxido de amôneo p.a. Deixar resfriar e, ajustar o pH a 8,5 se necessário.

a) Diluir a $2.000 \mathrm{ml}$ e extrair, várias vêzes, com $25 \mathrm{ml}$ de ditizona a $0,05 \%$, já purificada, até a fase aquosa assumir côr alaranjada e a porção de tetracloreto de carbono permanecer, predominantemente, de côr verde.

b) Transferir para funil de separação de 3 litros de capacidade e remover a coloração alaranjada com repetidos tratamentos de tetracloreto de carbono $(50 \mathrm{ml})$ sob agitação.

c) Acertar novamente o $\mathrm{pH}$ a 8,5 com hidróxido de amôneo 1:I e deixar a solução em geladeira durante 2 a 3 dias para a completa sedimentação do tetracloreto da porção aquosa.

3 - Hidróxido de amôneo, 1:1, destilado.

4 - Fenolftaleina, $1^{\prime} ;$ em etanol (95\%) destilado.

5 - Hidróxido de amôneo, $0,02 \mathrm{~N}$, destilado.

6 - Ditizona, $0,05 \%$ (preparo e purificação).

a) Dissolver $0,5 \mathrm{~g}$ de ditizona $\mathrm{em} 700 \mathrm{ml}$ de tetracloreto de carbono redestilado.

b) Filtrar para funil separador de 4 litros de capacidade, contendo $3.000 \mathrm{ml}$ de hidróxido de amôneo a 0,02 $\mathrm{N}$.

c) Após agitação durante 5 minutos, descartar a fase de tetracloreto de carbono.

d) Agitar, repetidas vêzes, com porções $(50 \mathrm{ml})$ de tetracloreto de carbono até este, ao separar-se, apresentar coloração verde intensa.

e) Adicionar 1 litro de tetracloreto de carbono e acidificar, ligeiramente com ácido clorídrico, 1:1. Nesta fase, a solução áquosa mudará de alaranjado à púrpura escura, c o tetracloreto de carbono assumirá coloração verde intensà.

f) Agitar durante 5 minutos e transferir a fase tetracloreto de carbono para um recipiente "Pyrex", conservando-a em geladeira.

7 - Tetracloreto de carbono, bi-destilado.

8 - Ácido clorídrico, $0,02 \mathrm{~N}$.

9 - Ácido clorídrico, $0,01 \mathrm{~N}$.

B - Tratamento da solução " $A$ " com ditizona em meio alcalino.

1 - Transferir $25 \mathrm{ml}$ da solução "A" de cada amostra em funis separadores de $125 \mathrm{ml}$ de capacidade, adaptados em um primeiro suporte para conter seis unidades. 
2 - Juntar $5 \mathrm{ml}$ de citrato de amóneo a $40 \%$.

3 - Adicionar uma gôta de fenolftalcina a $1 \%$.

4 - Acertar o pH a 8,5 com hidróxido de amôneo 1:1. 5 minutos.

5 - Adicionar $10 \mathrm{ml}$ de solução de ditizona e agitar durante

6 - Transferir a ditizona em tetracloreto de carbono, para uma segunda série de funís separadores.

7 - Lavar com 2 a $3 \mathrm{ml}$ de tetracloreto de carbono e proceder como item 6.

8 - Repetir os itens 5,6 e 7 até a fase aquosa apresentar coloração alaranjada, e o tetracloreto predominantemente verde.

9 - Adicionar $15 \mathrm{ml}$ de tetracloreto de carbono redestilado.

10 - Agitar clurante 5 minutos.

11 - Transferir a fase tetracloreto de carbono para os funís separadores referidos no item 6 .

12 - Desprezar a fase aquosa contida no primeiro funil separador.

C - Preparação da solução " $B$ ". (zinco).

1 - Pipetar $50 \mathrm{ml}$ de ácido cloridrico $0,02 \mathrm{~N}$ diretamente nos funis separadores mencionados na secção B, item 11 .

2 - Agitar durante, exatamente, 10 minutos.

3 - Transferir a fase tetracloreto de carbono $\mathrm{em}$ bequer de $100 \mathrm{ml}$ de capacidade.

4 - Adicionar $5 \mathrm{ml}$ de tetracloreto de carbono ao funil separador. Não agitar.

5 - Transferir o tetracloreto de carbono para o bequer citado no item 3. tico.

6 - Recolher a fase aquosa em recipientes de vidro ou plás-

Esı será a solução " $B$ " que contém o zinco.

D - Preparaçio da solução "C". (cobalto e cobre)

1 - Ao bequer mencionado na secção "C", item 5, adicionar $2 \mathrm{ml}$ de ácido perclórico, $60 \%$ \% $65 \%$.

2 - Evaporar, lentamente $\mathrm{cm}$ chaga elétrica, após cobri-los com vidro de relógio.

3 - Adicionar, se necessário, 1 a $2 \mathrm{ml}$ de ácido perclórico $60 \%$, até obter solução incolor. Evaporar o ácido após retirar o vidro de relógio.

4 - Dissolver o residuo $\mathrm{em} 10 \mathrm{ml}$ de ácido clorídrico $0,01 \mathrm{~N}$, cobrir com vidro de relógio $c$ aquecer ligeiramente.

5 - Transferir para frascos volumétricos de $25 \mathrm{ml}$, lavar o bequer com água redestilada e completar o volume.

Esta será a solução "C" que encerra o cobre e cobalto. 
Figura 1 - Representaço esquemátia das diversas fases para a separaça do zinco, cobalto e cobre isegundo LAZAl? (151, ('om modificaçōes)

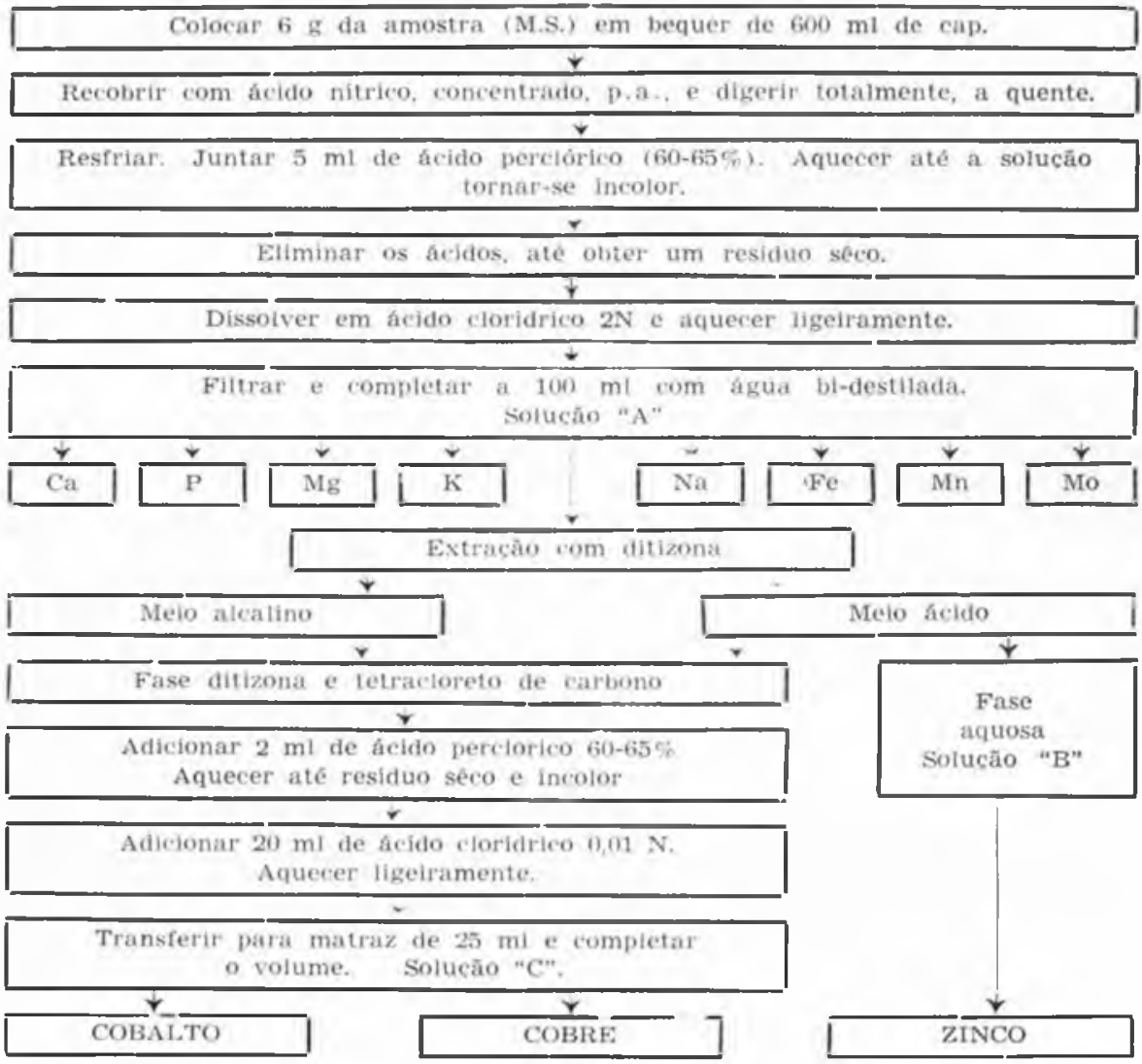

III - Determinação do zinco [segundo LAZAR (15)], A.O.A.C. (4) e Cowling \& Miller (5).

\section{A - Reagentes}

1 - Solução "tampão" para zinco.

Tomar $500 \mathrm{ml}$ de solução a 0,1 ; ; de dietilditiocarbamato de sódio, $400 \mathrm{ml}$ de citrato de amôneo a $40^{\prime} ;, 15 \mathrm{ml}$ de hidróxido de amôneo 1:1 e completar o volume a um litro com água bidestilada. Acertar o $\mathrm{pH}$ a 8,5 .

2 - Ditizona diluida.

Diluir 30 partes de ditizona purificada a 100 partes com tetracloreto de carbono, bi-destilado.

3 - Tetracloreto de carbono, redestilado.

4 - Solução de zinco $(1.000 \mu \mathrm{g} \mathrm{Zn} / \mathrm{ml})$. 
Dissolver 1 grama do metal zinco p.a., em $20 \mathrm{ml}$ de ácido clorídrico $1: 1$ e diluir a um litro com água bi-destilada. tilada.

5 - Solução de uso $(10 \mu \mathrm{g} \mathrm{Zn} \mathrm{ml})$.

Diluir $10 \mathrm{ml}$ da solução padrão a $1.000 \mathrm{ml}$ com água bi-des-

\section{B - Crrea padräo.}

Pipetar 0, 1, 2, 3, 4 e $5 \mathrm{ml}$ da solução de uso (10 $\mu \mathrm{g} \mathrm{Zn} / \mathrm{ml})$, juntar adequados volumes de ácido cloridrico $0,01 \mathrm{~N}$ para obter um volume total igual de $25 \mathrm{ml}$ e seguir o processo a partir do item " 2 " do método.

\section{C - Método.}

1 - Pipetar $25 \mathrm{ml}$ da solução " $B$ " $\mathrm{em}$ funil de separação de $125 \mathrm{ml}$ de capacidade.

2 - Adicionar $25 \mathrm{ml}$ cla solução "tampão" para zinco.

3 - Juntar 1 gôta de fenolftaleina a $1: 6$ e verificar o $\mathrm{pH}$. Se necessário, acrescentar gôtas de hidróxido de amôneo 1:1 até coloração rósea pálida.

4 - Pipetar $10 \mathrm{ml}$ da solução de ditizona diluída.

5 - Agitar durante exatamente 5 minutos.

6 - Transferir a fase ditizona para tubo de ensaio de $15 \mathrm{ml}$ de capacidade.

7 - Pipetar $3 \mathrm{ml}$ da soluçāo (item 6), transferindo-os para frasco volumétrico de $50 \mathrm{ml}$ e diluir ao volume com tetracloreto de carbono, redestilado.

8 - Proceder a leitura - porcento de transmissão - cm espectrofotômetro a $540 \mathrm{~m}_{\mu}$ e, usando como solução de referência tetracloreto de carbono redestilado.

\section{D - Cülculos.}

Multiplicar os microgramas de zinco, após deduzido o "blank", pela constante 1,333 para obter a concentração de zinco em p.p.m.

A matéria sêca foi obtida segundo método clássico do A. O. A. C. (4).

O número total de amostras (96), foi distribuido para fins estatísticos, por três gramíneas, quatro tipos de solos e duas colheitas - nas épocas de sêca e águas - sendo igualado a quatro o valor de cada classe.

A interpretação estatística seguiu modêlo de PIMENTEL GoMES (23). 


\section{RESULTADOS E DISCUSSÃO}

Os conteúdos de zinco encontrados nas plantas forrageiras, estão representados na figura 2 e os dados essenciais resultantes da análise estatística são vistos na tabela I.

\begin{tabular}{|c|c|c|}
\hline Fonte de Variacino & $\begin{array}{l}\text { Graus de } \\
\text { liberdade }\end{array}$ & $\begin{array}{l}\text { Quadrados } \\
\text { médios }\end{array}$ \\
\hline Forragens & 2 & 599 \\
\hline Epor'as & 1 & $14.628=0$ \\
\hline Solos & 3 & 1.510 \\
\hline Forragens $x$ solos & 6 & 363 \\
\hline Solos $x$ épocas & 3 & 136 \\
\hline Forragens $x$ epocas & 2 & 534 \\
\hline Residuo & $7 s$ & 564 \\
\hline
\end{tabular}

Os resultados revelaram que os niveis médios de zinco, observados nas três plantas forrageiras estudadas, não diferiram significantemente. D'outro lado, acentuada e significante discrepância foi assinalada entre épocas, nas quais, à semelhança do observado para o cálcio, magnésio (1), sódio (2), ferro e manganês (3), os teores de zinco superaram, na sêca, os encontrados na estação chuvosa, parecendo ainda não haver relação entre laxas do elemento na forragem e tipos de solo.

Em razão da escassez de observações feitas em relação ao teor de micronutrientes em espécies vegetais, mormente, $\mathrm{em}$ plantas forrageiras aqui estudadas, não nos é dada oportunidade de estabelecer cotejos, máxime se lembramos que Gladstones \& LoNeragan (10) afirmaram quase inexistir comparações criticas entre espécies de vegetais no atinente à sua capacidade de retirar do solo esses elementos para incorporá-los à parte aérea das plantas.

Adiantam, 1odavia, que há acentuadas diferenças entre espécies, no que tange à riqueza dêsses clementos, as quais parecem excrcer considerável influência não só na nutrição da planta como ainda no grau de adaptação da mesma a determinados tipos de solo (10). Como decorrência do variável estado de nutrição da planta, grandes oscilações são observadas no que concerne aos níveis de ingestão dos elementos por parte dos animais, mantidos 
em condições de pastejo. Segundo êsses autores (10), a concentração de zinco no caule e fôlhas das espécies, objetos de seus estudos, declinou com a idade, embora em diferentes gráus de intensidade.

Ėsses dados conflitam com os obtidos na presente investigaçāo, pois com o progredir da idade da planta, os conteủdos de zinco foram, para as três gramíneas, significantemente, mais elevados $\mathrm{em}$ relação aos registrados nas plantas mais novas. Os diferentes estágios de desenvolvimento das sementes observados nas plantas adulias, na época de sêca, parecem explicar essas diferenças pois, de acôrdo com Gladstones \& LoNeragan (10), as sementes abrigam a mais elevada concentração dêsse micronutriente em relação à planta total, na maturidade. De fato, as três gramineas aqui estudadas, apresentaram conteúdos em zinco da ordem de 65 e 40 p.p.m., respectivamente, na sêca e águas (tabcla II), enquanto Giadstones \& LONERAGaN (10), trabalhando com quatro espécies de gramineas, em estágio anterior à produção de sementes c, oriundas de solo não tratado pelo óxido de zinco, obtiveram, em três colheitas com intervalo de um mês, médias de 26, 15 e 13 p.p.m., consoante a ordem de amostragem.

TABFIdA II - Zinco, expresso em partes por milhäo sôbre matéria séca, de trủs gramineas. colhidas em diferentes tipos de solo e épocas do ano.

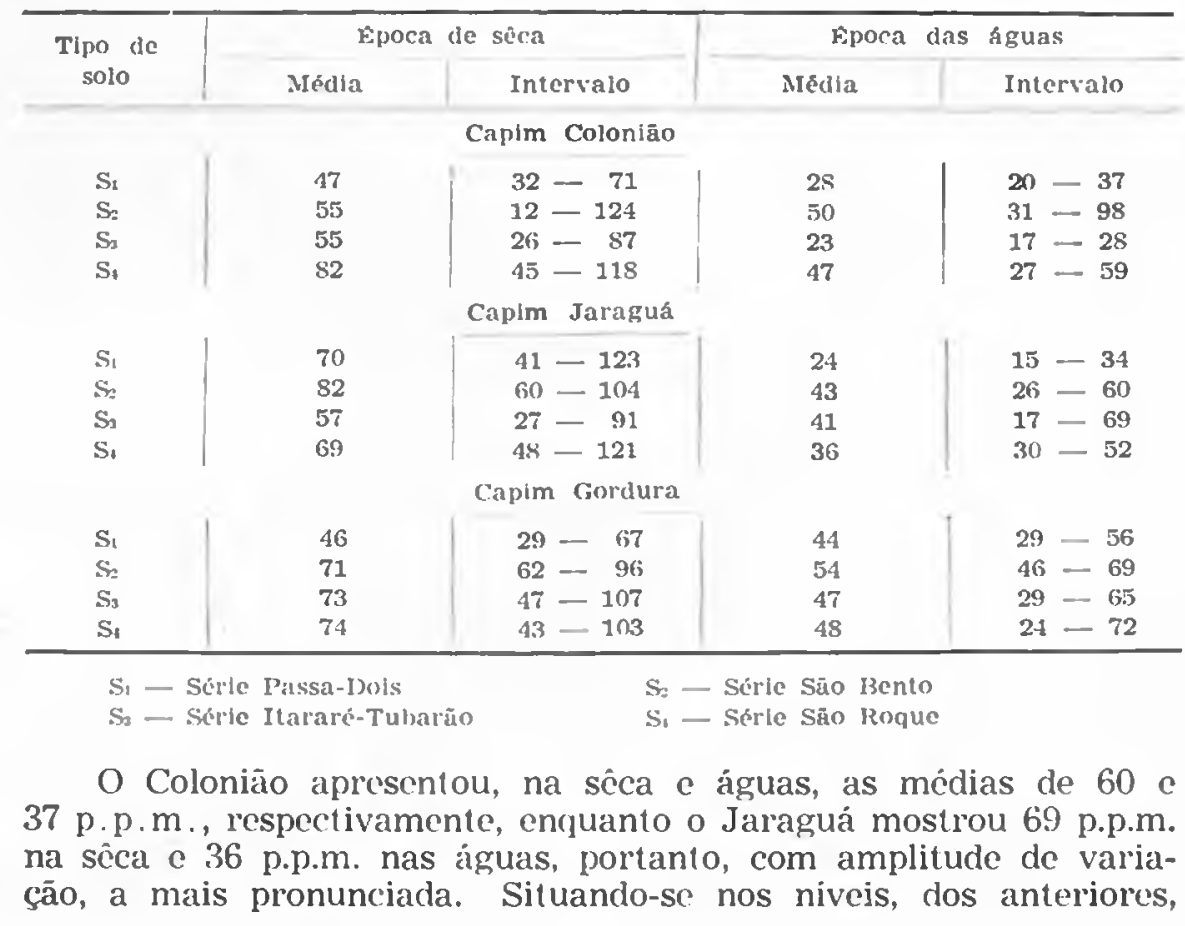


o Gordura, revelou a média de 66 p.p.m. na estação da sêca e 48 p.p.m., nas águas (tabela II e figura 2).

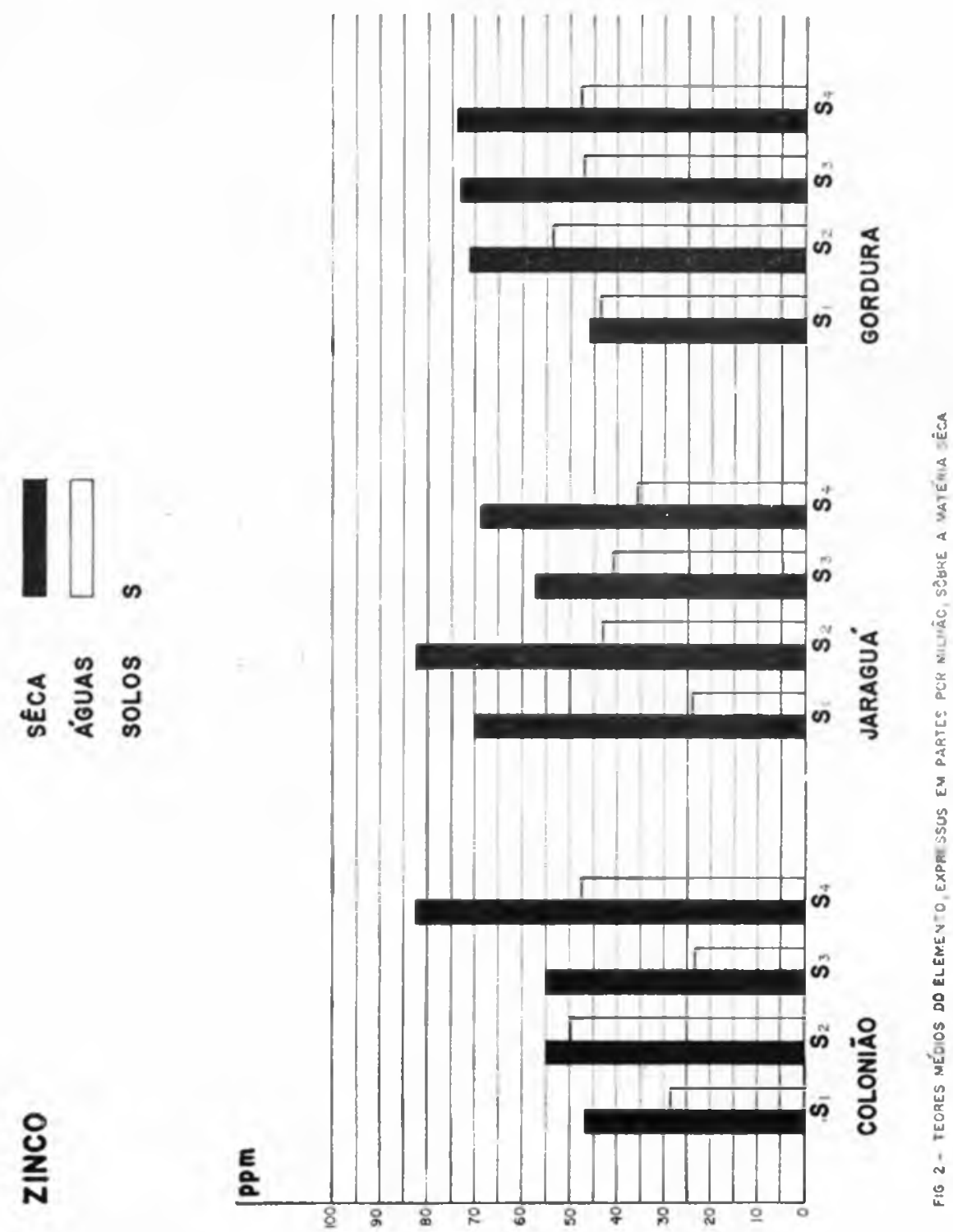

Transpurtando-nos para a área da nutrição animal, os resultados consignados na presente investigaçāo parecem fornecer subsídios para orientar eventuais possibilidades de identificação de zonas carenciais envolvendo insuficiência pura e simples de zinco, 
observada por diversos autores $(16,17,18,19)$ em bovinos, $(21$, 22) em ovinos, ou ainda devidas a desequilibrio das relações cálcio e zinco, descritas em bovinos $(8,12,13)$ e suinos $(14,25,29,31)$. D'outra parte, DyNNa \& HAVRe (8) identificaram a doença em bovinos jovens provocada por inadequada relação cobre e zinco. As suplementaçōes apenas de molibdeno ou da mistura zinco e molibdeno, agravaram o quadro clínico com acentuada repercussão sôbre o ganho de pêso. A administração da mistura zinco e cobre recuperava a saúde dos animais.

Isto posto e baseados nos niveis déste elemento, empregados com sucesso nos experimentos em bovinos, - Miller \& Miller (18), 40 p.p.m. e 260 p.p.m., CuNila et alii (6), 100 p.p.m., DYNNA \& HavRF (8), 53 p.p.m. de zinco e 10 p.p.m. de cobre c, em ovinos OTr et alii (21), 100 p.p.m., e O'TT et alii (22), 18 a 33 p.p.m. e 48 p.p.m. - parece licito conjeturar que os teores do elemento encontrados no presente trabalho não atenderiam às reais exigências dos animais, principalmente na estação chuvosa e em determinados municipios (tabela III).

TABEI AII - Zinco. expresso em partes por milhão sôhre matcíria sêtr, de très gramineas, colhidas em diferentes municipios e epocas do ano.

\begin{tabular}{|c|c|c|c|c|c|c|c|}
\hline \multirow{2}{*}{ Tipo de solo } & \multirow{2}{*}{ Município } & \multicolumn{2}{|c|}{ Coloniāo } & \multicolumn{2}{|c|}{ Jaràguá } & \multicolumn{2}{|c|}{ Gordura } \\
\hline & & Séca & Aguas & Sēca & Aguas & Sêca & Aguas \\
\hline \multirow{3}{*}{$\begin{array}{l}\text { Sćrle Passa-Dois } \\
\left(\mathrm{S}_{1}\right)\end{array}$} & Plrassununga & 32 & 37 & 123 & 3.1 & 44 & 53 \\
\hline & Plracicaba & 52 & 26 & 42 & 22 & 29 & 29 \\
\hline & Rio Claro & - & - & 72 & 17 & 67 & 39 \\
\hline \multirow{3}{*}{$\begin{array}{l}\text { Sérje Sũo Bento } \\
\left(S_{2}\right)\end{array}$} & Descalvado & - & - & $\$ 1$ & 26 & 96 & 49 \\
\hline & Sũo Pedro & 13 & 64 & 60 & 52 & 63 & 56 \\
\hline & Botucatú & 97 & 35 & 94 & 47 & - & 一 \\
\hline \multirow{5}{*}{$\begin{array}{l}\text { Sérle Itararé } \\
\text { Tubarüo (S) }\end{array}$} & Araras & 49 & 23 & - & 一 & 一 & - \\
\hline & S. Cruz das Palmelras & - & 一 & 66 & 48 & 一 & 一 \\
\hline & Limeira & 26 & 25 & 46 & 17 & 一 & 一 \\
\hline & Itú & 87 & 17 & 27 & 69 & 74 & 48 \\
\hline & Tiete & 58 & 28 & 91 & 30 & 72 & 46 \\
\hline \multirow{4}{*}{$\begin{array}{l}\text { Série Săo Roque } \\
\left(S_{t}\right)\end{array}$} & S. J. da Boa Vista & 89 & 52 & 121 & 52 & 101 & 72 \\
\hline & PInhal & 77 & 27 & 53 & 30 & 49 & 54 \\
\hline & S. J. do Rio Pardo & 45 & 59 & 48 & 31 & 一 & - \\
\hline & Cabreúva & 118 & 52 & 一 & 一 & 73 & 33 \\
\hline
\end{tabular}


Confirmando os achados obtidos por outros autores $(7,8,13$, 16), os resultados consignados no presente trabalho, sugerem a adoção de suplemento dêste micronutriente incorporado à mistura mineral destinada aos animais explorados em condições extensivas ou em regime de estabulaçāo.

Em outro sentido, as informaçōes sôbre a influência de vários fatôres dietéticos $(20,24,25,26,28)$, comuns nos alimentos destinados aos suínos e responsáveis pelo desencadeamento da doença, fazem prever a possibilidade de ocorrência de deficiências nessa espécic, em nosso meio. Embora consumindo grande quantidade de alimentos de base e tendo ainda livre acesso a piquetes de gramíneas mais tenras, os suinos ingerem teores insuficientes do elemento determinando efeitos danosos à sua saúde e produtividade.

Estudos, em andamento, ligados à riqueza em zinco e outros micronutrientes nas forragens adequadas aos suinos devem acrescer informaçōes de interêsse prático.

\section{SUMMARY}

The present experiment was undertaken to compare zinc concentrations in the tops of the pasture plants - Coloniāo (Panicum maximum), Jaraguá [Hyparrhenia rufa (Nees) Stapf] and Gordura (Melinis minutiflora) - three of the main forage species grown on restrict areas at the hinterland of São Paulo State, Brazil.

The samples were collected according with four types of soil, in dry and wet seasons in July and January, respectively, in order to find out the concentrations of this element.

An analysis of the variance of zinc contents in the whole tops showed that the three grasses differed no significantly but there were significant differences between dry season (6.5 p.p.m.) and damp season (40 p.p.m.).

As the seeds have a high amount of zinc, it seems that this fact has had the greatest influence in determining these wide differences between seasons, once the pasture plants presented different stages of development of their seeds at the harvest.

The mean zinc concentrations in dry season -60 p.p.m. ( $P a-$ nicum maximum), 69 p.p.m. [Hyparrhenia rufa (Nees) Stapf] and 66 p.p.m. (Melinis mimutiflora) - and in wet season - 37 p.p.m. (Panicum maximum), 36 p.p.m. [Hyparhenia rufa (Nees) Stapf I and finally, 48 p.p.m. (Melinis minntiflor $($ ) - emphasized the very low variation in zinc levels among grass species.

The very important role of this element in forage pastures and its relationships with calcium, copper, molybdenum and other dietetic factors, in order to avoid a nutritional disease in cattle, sheep and also in swine were discussed and the necessity to supply this micronutrient in mineral mixture, due to the reduced amounts encountered in the pasture plants was accentuated. 


\section{REFFRENCIAS BIBLIOGRÄFICAS}

1. ANDREASI, F.; VEIGA, J. S. M.; MENDONÇA JR., C. X.; PRADA, F.; BARNABE, R. C. - Levantamento dos elementos minerais em plantas forrageiras de áreas delimitadas do Fistado de São Paulo. I Cálcio, fósforo c magnèsio. Reı. Fuc. Med. vet., Sāo Paulo, $7(3): 583$ $604,1966-67$.

2. ANDRFASI, F.; MFNDONCA JR., C. X.; VFIGA, J. S. M.; PRADA, F.: MASOT'TI, N. - I,evantamento dos elementos minerais em plantas forrageiras de áreas delimitadas do Fistado de São Paulo. $I I$ - Sódio c potássio. Rev. Fiư. Med. vet., São Paulo, $\gamma(3): 605-614,1966-67$.

3. ANIDRFASI, F.; VEIGA, J. S. M.; PRADA, F.; MFNDONCA JR., C. $\mathrm{X}$. - Levantamento dos elementos minerais $\mathrm{cm}$ plantas forrageiras de áreas delimitadas do Fistado de Sāo Paulo. III — Ferro e manganês. Rèl. Fư: Med. vet., Sāo Paulo, r(4): 857-870, 1968.

4. ASSOCIATION OF OFFICIAL AGRICULTURAI, CHFMIS'TS Official methods of analysis. $7 .{ }^{\circ} \mathrm{ed}$. Washington, Association of Official Agricultural Chemists, 1950.

5. COWI.ING, II.; MILI.E.R, F. J. - Determination of small amounts of zinc in plant materials: A photometric dithizone method. Ind. Eng. Chem. Amal. Ed. 13:145-149, 1941.

6. CUNIA, T. J.; SHIRLliY, R. L.; CHAPMAN, H. L.; AMMERMAN, C. B.; DAVIS, G. K.; KIRK, W. G.; IIFNTGES JR., J. F. - Mineral for beef cattle in Florida. Florida Agric. Exp. Sha., Gainesville, Bul. 683: 21,1964 .

7. DYNNA, O.; HAVRl:, G. N. - Interrelationship of zinc and cooper in the nutrition of cattle. A complex zinc-copper deficiency. Acta Vet. Sccind. 4(3):197-208, 1963.

8. DYNNA, O.; HAVRF;, G. N. - Some obscruations of a complex zinccopper deficiency in cattle. Anuis IX Congr. Int. Pustugens, São Paulo, $1: 717-721,1965$.

9. GILSliKING, J. F.; SNIDFR. H. J.; GETZ, C. A. - Destruction of organic matter in plant material by the use of nitric and perchloric acids. Ind. Eng. Chem. Anul. Ed, z:185-186, 1935.

10. GLADSTONI:S, J. S.; LONERAGAN, J. F. - Mineral elements in temperate crop and pasture plants. I - Zinc. Aust. J. Agric. Res. 18 (3): $127-446,1967$.

11. GRAY, L. F.; FILLIS, G. H. - Some interrelationships of copper, molybdenum, zinc and lead in the nutrition of the rat. J. Nut. 40(3): $441-452,1950$.

12. HAARANF, S. - The effect of zinc on itching tail root eczema in cattle. Nord. Vet. Med., 14(4):265-269, 1962.

13. HAARANEN, S. - Some observations on the zinc requirement of cattle for the prevention of itch and hair licking at different calcium levels in the feed. Nord. Vet. Med., 15(7-8):536-542, 1963.

14. HOF:FH, J, A.; MILI.ER, $\%$ R.: ULLRFY, D. F.; RITCHF, II. D.; LUF.CKF, R. W. - Interrelationships between calcium, zinc, iron and copper in swine feeding. J. Anim. Sci., 19(1):249-259, 1960. 
15. LAZAR, V. A., comp., - Methods for the determination of mineral elements in plant tissue. $U$. S. Plent, Soil and Nutrition Luborutory: $1-32$, s.d.

16. LFGG, S. P.; SFARS, L. - Zinc sulphate treatment of parakeratosis in cattle. Nuture, Iondon, $186: 1061-1062,1960$.

17. MII.LER, J. K.; MILI.ER, W. J. - Development of zine deficiency in Holstein calves fed a purified diet. J. Deiry Sci. 4.i(2):1854-1856, 1960.

18. MILLFR, J. K.; MIIJ,FR, W. J. - Fixperimental zinc deficiency and recovery of calves. J. Nut. $76(4): 467-474,1962$.

19. MILLS, C. F.; DALGARNO, A. C.; WILI IAMS, R. B.; QUARTMAN, J. - Zine deficiency and zine requirements of calves and lambs. Brit. J. Nut. 21(3):751-768, 1967.

20. OBFRI.EAS. D.; MLHRER, M. F.; O'DELL. B. L. - Jiffects of phytic acid on zinc availability and parakeratosis in swine. J. Anim. Sci. 21 (1) :57-61, 1962.

21. O'T', F. A.; SMITH, W. H.; STOB, M.; BF.FSON, W. M. - Zine deficiency syndrome in the young lamb. J. Nut. 82(1):41-50, 1964.

22. OTT, E. A.; SMITH, W. I.; STOB, M.; PARKFI, H. F.; HARRINGTON, R. B.; BEESON, IV. MI. - Zine requirements of the growing lamb fed a purified diet. J. Nut. $8 \%(4): 458-463,1965$.

23. PIMINTFi. GOMies, F. - Cur'so de Fstatistica Experimental. 2." ed. Piracicaba, Fdiçōes Didáticas, 1963.

24. POND, W. G.: CHAPMAN, Ph.; WALKFR, F. JR. - Influence of dietary zinc, corn oil and cadmium on cortain blood components, wright gain and parakcratosis in young pigs. J. Anim. Sri. 25(1):122-127, 1966.

25. POND, W. G.; JONWS, J. R.; KROFNING, G. II. - Fffect of level of dietary zinc and source and level of corn on performanee and incidence of parakeratosis in weanling pigs. J. Anim. Sei. 2:3(1):16-20, 1964 .

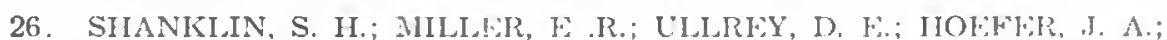
LE'FCKli, R. IV. - Zine requirement of baby pigs on cascin diets. $J$. Nut. 96(1):101-108, 1968.

27. SMITH, S. F.; I.ARSON, F. - Zine toxicity in rats. Antagonistic offects of copper and liver. J. Biol. Chem. /6:3:29-38, 1946.

28. SMITH, W. H.; PLCMLFE, M. P.; BFESON, WV. M. - Fiffect of source of protein on zinc requirement of the growing pig. J. Anim. Sci., 21 (3) :399-405, 1962.

29. TLCKF.R. II. F.; SALMION, W. D. - Parakeratosis or zinc deficiency discase in the pig. Proc. Suc. Exp. Biol. Med. 88:613-616, 1955.

30. CNDERWOOD, E. J. - Trace elements in Human and Animal Nutrition. New York, Academic Press Inc., 1956.

31. VALEE, B. L. - Biochemistry, physiology and pathology of zinc. Physiol. Rel. $39: 443-490,1959$. 